\title{
Clinicopathological Study of Epithelial Metaplastic Breast Cancer
}

\author{
Masahiro Kitada*, Shunsuke Yasuda, Nana Takahashi, Satoshi Okazaki, Kei Ishibashi, Satoshi Hayashi \\ Department of Breast Disease Center, Asahikawa Medical University, Asahikawa, Japan \\ Email: ^k1111@asahikawa-med.ac.jp, a090066@ed.asahikawa-med.ac.jp, kyokui080026@gmail.com, syugoshin.19851221@gmail.com, \\ kei_dod@hotmail.com,shayashi@asahikawa-med.ac.jp
}

How to cite this paper: Kitada, M., Yasuda, S., Takahashi, N., Okazaki, S., Ishibashi, K. and Hayashi, S. (2016) Clinicopathological Study of Epithelial Metaplastic Breast Cancer. Journal of Cancer Therapy, 7, 10391044.

http://dx.doi.org/10.4236/jct.2016.713100

Received: November 20, 2016 Accepted: December 19, 2016

Published: December 22, 2016

Copyright $\odot 2016$ by authors and Scientific Research Publishing Inc. This work is licensed under the Creative Commons Attribution International License (CC BY 4.0).

http://creativecommons.org/licenses/by/4.0/

\section{Abstract}

Introduction: Metaplastic breast cancer $(\mathrm{MBC})$ is a rare pathological type with an incidence rate of not more than $1 \%$, and has been reported to be often detected after its progression and highly malignant with a high proportion of triple negative type tumors, with poor outcomes as compared to IDC [1] [2] [3]. We analyzed clinicopathological characteristics of patients who underwent surgery for epithelial MBC at our department. Patients and Methods: From January 2000 to March 2014, a total of 2120 patients underwent surgery for breast cancer, and MBC was diagnosed in 15 of these patients. Fourteen of the 15 had epithelial MBC and were included in this study. The present study compared clinopathological characteristics of MBC with those of IDC of triple negative type (TN type group) and IDC of non-triple negative type (IDC group). Results: Breast conserving surgery was performed in 7 patients with MBC (50\%), a proportion clearly lower than the $64.3 \%$ in the IDC group. The mean tumor size was $3.8 \mathrm{~cm}$, which was greater than the $2.13 \mathrm{~cm}$ in the TN type group and the $1.7 \mathrm{~cm}$ in the IDC group. About nuclear grade, the proportion of grade III was $57.1 \%$, markedly higher than the $38.6 \%$ in the TN type group and the $12.6 \%$ in the IDC group. All patients were estrogen receptor (ER) and progesterone receptor $(\mathrm{PgR})$ negative; 11 patients were TN type tumors and 3 were HER2 type. Conclusion: We studied patients who underwent surgery for epithelial MBC. The examined cases showed clinopathological characteristics of the disease, including large tumors with a highly malignant nature at the initial detection, higher Ki-67 levels, ER and PgR negativity (all cases), mostly TN type, and a high recurrence rate.

\section{Keywords}

Breast Cancer, Metaplastic Breast Cancer, Triple Negative Type, Epithelial-Mesenchymal Transition 


\section{Introduction}

Metaplastic breast cancer (MBC), a special form of breast cancer, refers to a group of various invasive ductal carcinomas (IDC) having a phenotype of either non-glandular epithelium or a mix of non-glandular epithelium and mesenchymal stem cells. MBC is a rare tissue type with an incidence rate of not more than $1 \%$, and has been reported to be often detected after its progression and highly malignant with a high proportion of triple negative type tumors, with poor outcomes as compared to IDC [1] [2] [3]. MBC has recently attracted considerable attention from the perspectives of the epithelialmesenchymal transition (EMT) concept, molecular pathology studies, and targeted therapy development [4] [5]. We herein analyzed clinicopathological characteristics of patients who underwent surgery for epithelial MBC at our department.

\section{Patients and Methods}

From January 2000 to March 2014, a total of 2120 patients underwent surgery for breast cancer, and $\mathrm{MBC}$ was diagnosed in 15 of these patients. In this study, epithelial MBC was applied and mesenchymal MBC was excluded. Fourteen of the $15(0.67 \%)$ had epithelial MBC and were included in this study. All patients were female with a mean age of 52.9 years (range: 33 to 74 years), younger than the mean age of 56.9 years in IDC patients. Two patients who had been diagnosed with IDC of non-special type (NS type) based on preoperative core needle biopsy received primary systemic therapy (PST). There was no difference in the background factors in each group. The present study compared clinopathological characteristics of MBC with those of IDC of triple negative type (TN type group) and IDC of non-triple negative type (IDC group). This study was conducted in compliance with the Declaration of Helsinki.

\section{Results}

The background factor of the patient was shown in Table 1, and the clinicopathological examination of MBC with those of IDC of triple negative type (TN type group) and IDC of non-triple negative type (IDC group)was shown in Table 2. 1) Stage, operative procedure, and tissue type: The stage classification of cancer was I in 5 patients and II or higher in 9 patients (64.2\%). In the IDC group, stage II and higher accounted for $39.3 \%$, indicating a higher proportion of advanced cancer cases among those with MBC (Figure 1). Breast conserving surgery was performed in 7 patients with MBC (50\%), a proportion clearly lower than the $64.3 \%$ in the IDC group. The tissue type classification was squamous cell carcinoma in 7 patients, adenosquamous carcinoma in 4, spindle cell carcinoma in 2, and squamous cell carcinoma + spindle cell carcinoma in one. 2) Oncological characteristics: The mean tumor size was $3.8 \mathrm{~cm}$ (range: 0.4 to $9.0 \mathrm{~cm}$ ), which was greater than the $2.13 \mathrm{~cm}$ in the TN type group and the $1.7 \mathrm{~cm}$ in the IDC group. Only 1 patient had lymph node metastasis. The degree of nuclear atypia was grade I in 2 patients, grade II in 4 , and grade III in 8 ; the proportion of grade III was $57.1 \%$, markedly higher than the $38.6 \%$ in the TN type group and the $12.6 \%$ in the IDC group (Figure 2). The mean Ki-67 level was 55.4\%, similar to the $53.5 \%$ in the TN type group 
Table 1. Case of epitherial metaplastic carcinoma.

\begin{tabular}{ccccccccc}
\hline N0 & Age & Pathology & Stage & Size & Grade & ER & PgR & HER3 \\
\hline 1 & 46 & SCC & $2 \mathrm{a}$ & 22 & II & - & - & $1+$ \\
2 & 53 & SCC & $2 \mathrm{a}$ & 32 & III & - & - & $3+$ \\
3 & 58 & SCC & 1 & 9 & II & - & - & $3+$ \\
4 & 55 & SCC & 1 & 17 & II & - & - & - \\
5 & 64 & SCC & $2 \mathrm{a}$ & 29 & II & - & - & - \\
6 & 33 & Adenosquamous ca & 1 & 4 & I & - & - & - \\
7 & 54 & Spindle cell ca & 1 & 20 & III & - & - & - \\
8 & 55 & Adenosquamous ca & $2 \mathrm{~b}$ & 70 & III & - & - & - \\
9 & 54 & Adenoaquamous ca & $2 \mathrm{a}$ & 25 & III & - & - & - \\
10 & 75 & Adenosquamous ca & $2 \mathrm{a}$ & 25 & III & - & - & $3+$ \\
11 & 41 & Spindle cell ca & $2 \mathrm{~b}$ & 44 & III & - & - & $3+$ \\
12 & 42 & SCC & $3 \mathrm{~b}$ & 90 & III & - & - & - \\
13 & 42 & SCC+ spindle cell ca & $2 \mathrm{a}$ & 28 & II & - & - & $1+$ \\
14 & 69 & SCC & 1 & 90 & III & - & - & - \\
\hline
\end{tabular}

SCC: Squamous cell carcinoma, ER: estrogen receptor PgR: progesterone receptor; HER2: human epidermal growth factor receptor $2,{ }^{*}$ size: tumor size $(\mathrm{mm})$.

Table 2. Clinicopathological characteristics of metaplastic breast cancer and invasive ductal carcinoma (non TN type and TN type).

\begin{tabular}{cccc}
\hline & Metaplastic ca & IDC(TN type) & IDC(non TN type) \\
\hline Tumor size (average value) & $3.2 \mathrm{~cm}$ & $2.1 \mathrm{~cm}$ & $1.7 \mathrm{~cm}$ \\
Grade III & $58.3 \%^{*}$ & $69.6 \%^{*}$ & $12.6 \%$ \\
Ki-67 & $53.8 \%^{*}$ & $53.3 \%^{*}$ & $24.2 \%$ \\
Ly(+) & $16.7 \%$ & $19.8 \%$ & $13.5 \%$ \\
V(+) & $25.0 \%$ & $13.7 \%$ & $10.5 \%$ \\
Breast conserving surgery & $50.0 \%$ & $62.3 \%$ & $64.3 \%$ \\
Recurrence rate & $14.3 \%$ & $8.3 \%$ & $9.2 \%$ \\
\hline
\end{tabular}

${ }^{*} \mathrm{p} \leq 0.05$.

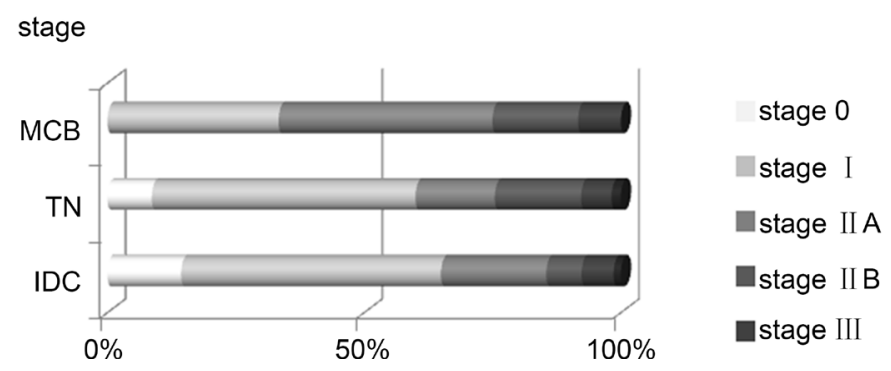

Figure 1. Pathological staging of metaplastic breast cancer and other control group. 


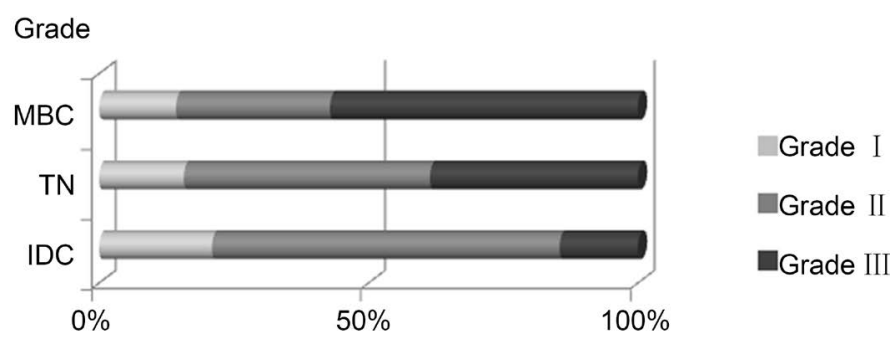

Figure 2. Nuclear grade of metaplastic breast cancer and other control group.

but significantly higher than the $24.2 \%$ in the IDC group. Vascular invasion parameters showed no significant differences; ly(+) was $16.7 \%$ versus $19.8 \%$ in the TN type group and $13.5 \%$ in the IDC group; $\mathrm{v}(+)$ was $25.0 \%$ versus $13.7 \%$ in the TN type group and $10.5 \%$ in the IDC group. In the 2 patients given pre-operative PST, chemotherapy response was determined to be grade 1a in both. 3) Biological characteristics: All patients were estrogen receptor (ER) and progesterone receptor (PgR) negative; 11 patients were classified as having TN type tumors and 3 as having HER2 type. 4) Postoperative adjunctive therapy and outcome: No postoperative therapy was administered to 2 patients who declined treatment, and standard therapy with anthracycline or taxane was administered according to established guidelines to all other patients, in the same manner as for IDC. Local recurrence was reported 7 years post-surgery in 1 patient who had undergone breast conserving surgery for squamous cell carcinoma. This patient had rejected postoperative pharmacotherapy and received radiotherapy and was under follow-up observation alone. After the recurrence, this patient underwent mastectomy and is currently being treated. Another patient experienced bone metastasis but none of the 14 patients have died, to date. The recurrence rate of $14.3 \%$ with $\mathrm{MBC}$ is higher than the $9.2 \%$ in the TN type group and the $8.3 \%$ in the IDC group.

\section{Discussion}

$\mathrm{MBC}$ is a rare tissue type with an incidence of approximately $1 \%$. The WHO classification categorizes $\mathrm{MBC}$ into two groups: tissue morphology of pure epithelium (epithelial type) and a mixture of epithelial tissue with mesenchymal tumor cells (mixed type). The epithelial MBC can be squamous cell carcinoma, adenosquamous carcinoma, spindle cell carcinoma, mucoepidermoid carcinoma, etc. On the other hand, mixed type $\mathrm{MBC}$, which was not the target of the present study, may be carcinoma with bony and cartilaginous metaplasia, matrix-producing carcinoma, or carcinosarcoma. MBC reportedly has a poor outcome due to large tumor size and rapid growth [1] [2] [3].

Relevant oncological factors include not only tumor size and lymph node metastasis, but also the malignancy of the tumor, as indicated by nuclear atypia (grade), the proliferation marker Ki-67, and vascular invasion parameters (ly and v factors). Large tumors are characteristic of $\mathrm{MBC}$, and the present study indicated the size of MBC to exceed that of IDC. The grade distribution was generally similar to that of TN type, but MBC had a higher proportion of grade III and a higher frequency of vascular invasion. 
With respect to the greater malignancy and tumor size, the rate of lymph node metastasis was low (only 1 patient), which appears to be a key feature of MBC. Poor prognostic factors for this tissue type include a tumor size of $4.0 \mathrm{~cm}$ or greater, cutaneous invasion, and lymph node metastasis. In the present study, outcomes were generally good with only 1 case each of local recurrence and distant metastasis and no case of death.

Regarding biological factors, most patients were negative for hormone receptors and HER2, although some had HER2-positive cancer. Characteristics similar to those of TN type have been reported [6] [7]. Therefore, hormone therapy and molecular targeted therapy are not feasible and chemotherapy is the only option for postoperative adjunctive therapy. At the present time, no MBC-specific pharmacotherapy is available, and anthracyclines and taxanes are usually used based on the therapeutic strategy for IDC. Currently, expectations are rising for the use of bevacizumab, which can be administered for breast cancer, and molecular targeted agents, such as cetuximab which is used for EGFR-positive colorectal cancer [1].

The concept of EMT is also attracting attention in the field of cancer research. Tumor growth factor (TGF) $\beta$ and E-cadherin are among the representative molecules involved in EMT. Particularly in triple negative breast cancer, overexpressions of EMT-associated genes (e.g., TWIST1 and SNAIL1) are significantly higher than in other tumor types, and these genes are known to regulate the expression of E-cadherin [8] [9]. Lower expression of E-cadherin is associated with partial EMT, and future studies elucidating the pathology of metaplastic cancer may lead to the discovery of new target molecules.

\section{Conclusion}

We studied patients who underwent surgery for epithelial MBC. The examined cases showed clinopathological characteristics of the disease, including large tumors with a highly malignant nature at the initial detection, higher Ki-67 levels, ER and PgR negativity (all cases), mostly TN type, and a high recurrence rate. As elucidation of the pathology of metaplastic cancer is likely to lead to the discovery of new target molecules involved in EMT, the accumulation of case studies of MBC and other metaplastic tumors is necessary.

\section{Consent}

Informed consent was obtained from each patient for publication. A copy of the written consent is available for review by the Editor-in-Chief of this journal.

\section{Conflict of Interests}

The authors declare that they have no conflict of interests.

\section{Acknowledgements}

The authors declare that they have no conflict of interests. 


\section{References}

[1] Beatty, J.D., Atwood, M., Tickman, R. and Reiner, M. (2006) Metaplastic Breast Cancer: Clinical Significance. The American Journal of Surgery, 191, 657-664.

https://doi.org/10.1016/j.amjsurg.2006.01.038

[2] Luini, A., Aguilar, M., Gatti, G., Fasani, R., Botteri, E., Brito, J.A., Maisonneuve, P., Vento, A.R. and Viale, G. (2007) Metaplastic Carcinoma of the Breast, an Unusual Disease with Worse Prognosis: The Experience of the European Institute of Oncology and Review of the Literature. Breast Cancer Research and Treatment, 101, 349-353.

https://doi.org/10.1007/s10549-006-9301-1

[3] Jung, S.Y., Kim, H.Y., Nam, B.H., Min, S.Y., Lee, S.J., Park, C., Kwon, Y., Kim, E.A., Ko, K.L., Shin, K.H., Lee, K.S., Park, I.H., Lee, S., Kim, S.W., Kang, H.S. and Ro, J. (2010) Worse Prognosis of Metaplastic Breast Cancer Patients Than Other Patients with Triple-Negative Breast Cancer. Breast Cancer Research and Treatment, 120, 627-637.

https://doi.org/10.1007/s10549-010-0780-8

[4] Gwin, K., Buell-Gutbrod, R., Tretiakova, M. and Montag, A. (2010) Epithelial-to-Mesenchymal Transition in Metaplastic Breast Carcinomas with Chondroid Differentiation: Expression of the E-Cadherin Repressor Snail. Applied Immunohistochemistry \& Molecular Morphology, 18, 526-531. https://doi.org/10.1097/PAI.0b013e3181e8d54b

[5] Weigelt, B., Kreike, B. and Reis-Filho, J.S. (2009) Metaplastic Breast Carcinomas Are BasalLike Breast Cancers: A Genomic Profiling Analysis. Breast Cancer Research and Treatment, 117, 273-280. https://doi.org/10.1007/s10549-008-0197-9

[6] Gerhard, R., Ricardo, S., Albergaria, A., Gomes, M., Silva, A.R., Logullo, Â.F., CameselleTeijeiro, J.F., Paredes, J. and Schmitt, F. (2012) Immunohistochemical Features of ClaudinLow Intrinsic Subtype in Metaplastic Breast Carcinomas. The Breast, 21, 354-360. https://doi.org/10.1016/j.breast.2012.03.001

[7] Lester, T.R., Hunt, K.K., Nayeemuddin, K.M., Bassett Jr., R.L., Gonzalez-Angulo, A.M., Feig, B.W., Huo, L., Rourke, L.L., Davis, W.G., Valero, V. and Gilcrease, M.Z. (2012) Metaplastic Sarcomatoid Carcinoma of the Breast Appears More Aggressive Than Other Triple Receptor-Negative Breast Cancers. Breast Cancer Research and Treatment, 131, 41-48.

[8] Giuliano, M., Giordano, A., Jackson, S., et al. (2011) Circulating Tumor Cells as Prognostic and Predictive Markers in Metastatic Breast Cancer Patients Receiving First-Line Systemic Treatment. Breast Cancer Research, 13, R67. https://doi.org/10.1186/bcr2907

[9] Lombaerts, M., van Wezel, T., Philippo, K., et al. (2006) E-Cadherin Transcriptional Downregulation by Promoter Methylation But Not Mutation Is Related to Epithelial-toMesenchymal Transition in Breast Cancer Cell Lines. British Journal of Cancer, 94, 661671. https://doi.org/10.1038/sj.bjc.6602996 
Submit or recommend next manuscript to SCIRP and we will provide best service for you:

Accepting pre-submission inquiries through Email, Facebook, LinkedIn, Twitter, etc. A wide selection of journals (inclusive of 9 subjects, more than 200 journals)

Providing 24-hour high-quality service

User-friendly online submission system

Fair and swift peer-review system

Efficient typesetting and proofreading procedure

Display of the result of downloads and visits, as well as the number of cited articles

Maximum dissemination of your research work

Submit your manuscript at: http://papersubmission.scirp.org/

Or contact jct@scirp.org 